\title{
Application of Closed Cycle Progressive Teaching Mode of "Internet + teaching" in Vocational Colleges
}

\author{
Jun Luo ${ }^{1, a}$ and Yulan $\mathrm{Yu}^{2, \mathrm{~b}^{*}}$ \\ ${ }^{1}$ Department of Management, Guangdong University of Science \& Technology, Dongguan 523083, \\ Guangdong, China; \\ 2Department of Psychology/ Research Center for Quality of Life and Applied Psychology, \\ Guangdong Medical University, Dongguan 523808, Guangdong, China \\ a luojun003@126.com, b psyyulan@126.com
}

Keywords: Internet; Internet + teaching; Learning platform; Teaching mode

\begin{abstract}
The research contents were program planning of investigate and survey in the course of management course "market research and prediction". Curriculum knowledge points were studied in closed cycle progressive learning platform which were consists of learning mutual aid platform, interactive reflection platform, practical innovation platform and result display platform and different teaching methods with "Internet + teaching" mode were designed and implemented in these learning platforms to improve students' learning interest, attitude and ability. Students can realize self-study and mutual help learning, internalization and understanding of knowledge, practice and application of knowledge.

"Internet +" has been in the rapid development of Chinese industries with the network information era coming, and China education also has innovate synchronously based on internet information technology and resources. The emergence of the "Internet + teaching", "Internet + class" and "Internet + learning" and "teaching Internet + management" and "Internet + educational evaluation" create a new situation with internet education ".
\end{abstract}

\section{The Foundation of Application Research}

Every key knowledge points were studied in closed cycle progressive learning platform which were consists of learning mutual aid platform, interactive reflection platform, practical innovation platform and result display platform (Table 1). This kind of teaching mode not only met with the need of personnel training in vocational colleges but also making full use of the internet platform and internet resources. Different and suitable teaching methods in different platforms, are designed to carry out the interactive teaching of the Internet, and finally the learning mode of "independent learning and mutual learning, internalization and understanding of knowledge, practice of knowledge to knowledge application" was realized.

Table 1 closed cycle progressive teaching mode of "Internet + teaching"

\begin{tabular}{|c|c|}
\hline Learning mutual aid platform & Interactive reflective platform \\
\hline Individual learning situation platform & Problem interaction \\
MOOC, World University City & Homework reflection \\
Team learning support platform & Game participation \\
Dormitory, class learning mutual aid platform & role playing \\
Wechat group, QQ group & case analysis \\
\hline Achievement sharing & Innovation Institute \\
\hline Characteristic interpretation & Special training \\
Results show, PPT, Material object & Laboratory training \\
video and so on & Classroom training, cases, video \\
Achievement display platform & Practice and innovation platform \\
\hline
\end{tabular}




\section{Application of Closed Cycle Progressive Teaching Mode of "Internet + teaching" in Vocational Colleges}

Research Objects. Individual object: every student in the third grade of department of management in one college. Team object: a team consisting of dormitories. Group object: class as a research and discussion unit.

Research Contents. The case was " Long Jiang pig's knuckle convenient fast food ".The teacher introduced the key of pre-start, start-up and post-business of the case to every students in class and require each group to complete the systematic design of the research plan and the design of each project content according to the specialized course of market research and prediction.

Research Methods. The teacher modularized the key knowledge of each project in the research plan and split them into teaching units and . Different teaching methods such as video learning, case study and discussion, task driving and so on were adapted. The teacher created the student's learning situation platform and mutual aid platform based on the four closed-loop circular progressive learning platform which consisting o learning mutual aid platform, interactive reflection platform, practical innovation platform and achievement display platform to cultivate students' self-management ability, independent learning ability and teamwork spirit.

Application Research. The first step: The definition of the ultimate task----plan investigate and survey Project for tasks and modularization for key knowledge, that is identify research questions, clarify research purposes, design research contents, choose research methods, design questionnaires and design sampling plans.

The second step: Independent study before class. The personal learning situation platform in the learning aid platform is carried out in the world university town (teachers and students have personal account and class learning management platform). Teachers should use the Internet resources, such as MOOC, micro class, Youku and Baidu library and so on to find relevant video related to the modular knowledge of this course. Or the teacher self-made teaching Micro-video and uploaded some knowledge point to the world university town. Teachers can monitor which students have watched this video in the world university town. Each project corresponded to a task of a design class and every student was required to finished the task and uploaded it to the world university town's operation system and the teacher read it, which shaped students' independent learning ability and independent thinking ability.

The third step: Interactive reflective learning in class. Interactive reflection platform was carried out in two modes. One was the students were asked to write their own experiences and questions into the class after learning in the mutual aid platform. The teacher organized their students to interact, reflect and learn their PPT documents, and the teacher can correct, guide and feed back. The other was that teachers designed specific questions for the students' according to the learning situation of pre-class and the knowledge points of the course. In the classroom, the teacher asked questions to guide students to reflect, interact and learn. In an appropriate case, the teacher designed the knowledge point as a case, game, or performance to play the role of the student, and let the students feel the knowledge. Homework reflection, problem interaction, game participation, role playing, case analysis and PPT results display of student team group and so on strengthened the interactive reflection platform of core knowledge points and improved the students' learning enthusiasm and class learning atmosphere.

The fourth step: Internalization and practice of knowledge points in class / after class. The internalization and practice of knowledge points can be organized in the form of classroom practice, laboratory training, special training, practical training and social practice in innovation and entrepreneurship colleges, and create a unique platform for practical innovation.The classroom practice is to strengthen the further understanding of the knowledge points and the application transformation on the platform of interactive reflection, give students a different case, organize students to carry out case analysis or application design. For example, there is a statistical mathematics example in the textbook of market research and prediction. 1500 consumers in a city were investigated and 5\% of the consumers were selected as samples. The data were as follows: the sample number was 75 , the average consumption expenditure was 434.4 yuan per person, and the 
standard deviation of the shopping consumption was 46.8 yuan, and the average error of the sampling average was calculated. This is a statistical question, and we can translate it into the relevant items in the research program (including the research object, the research place, the research purpose, the research method, the data, the total, the sample, the sampling method, etc.). Even the teacher can ask how 434.4 and 46.8 of the examples come from, let the students not only know what it is but know why it is, instead of just training students' formula calculation. Laboratory training needs to be carried out in the laboratory For example, the telephone interview method in the research method can complete the training in the telephone interview laboratory, and promote the practice understanding of the students. Organizing students to participate in related projects of innovation and entrepreneurship college and enter the company to visit, part time or practice in class time, weekend and winter and summer vacation if there are some opportunities. All these will combine theory with practice to promote internalization and understanding of knowledge..

Step five: Learning enthusiasm and the molding of learning motivation.A sense of accomplishment can enhance self-confidence and initiative in people's learning and life, and enable people to take the initiative to meet challenges. Contemporary college students have strong desire for expression, so it is necessary to provide students with opportunities to appear in the teaching process, namely, the achievement display platform. The students' individual or team will be able to display the PPT, design, material, and video produced at least in the class platform. The teacher organizes the student to carry on the characteristic explanation and the comment together. Even students' results can be displayed in the university campus, the campus network platform or the Wechat public number and so on to improve their motivation and interest in learning.

\section{Conclusion}

About application of closed cycle progressive teaching mode of "Internet + teaching" in Vocational Colleges, on the one hand, we should consider the ability of students to learn knowledge and their attitudes towards learning. Through the application of closed circuit progressive teaching platform, the learning atmosphere of dormitory, class and campus was built, and the environment of autonomous learning and mutual learning was created, which was more conducive to the students to learn actively under the atmosphere of the atmosphere and the environment. On the other hand, teachers should make full use of Internet resources, such as MOOC "famous school + famous teacher + famous class" resources, micro lessons, Youku and so on. Teachers use the internet platform as a teaching tool to let students feel, experience, practice, think, internalize, and integrate knowledge and social practice, which will meet the needs of the educational development in the Internet age.

This paper is supported by Dongguan city occupation technology education development research project of 13th Five-Year Plan(DZH1718031);Education and teaching reform project of higher education in Guangdong Province(2016258);Guangdong Adult Education Association adult education research program(key projects)(Ycx161008).

\section{Reference}

[1] Y.P.Yu.Exploration and reflection of "Internet + teaching" teaching model[J].Journal of Heilongjiang College of Education, Vol.9(2015)No.35,p.62-64.

[2] M.Xie. The study on teaching wisdom under the background of "Internet +Education" .(MS.the Jilin University,China 2016):p.1-62.

[3] X.Lv. Investigation and Research on Internet Teaching in Higher Forestry Universities in the era of Internet plus . (MS.Beijing Forestry University,China 2016):p.1-48.

[4] Peng L, Xiaoping Z. Social Stratification and Cooperative Behavior in Spatial Prisoners' Dilemma Games [J]. PLOS ONE, 2015, 10(7): e0131005.

[5] Qingjun Wang, Yibo Li and Xueping Liu. Analysis of Feature Fatigue EEG Signals Based on Wavelet Entropy[J]. International Journal of Pattern Recognition and Artificial Intelligence, 2018, 32(8):1854023 